\title{
Kinetics and Mechanism of Hydrolysis of Acetylthiocholine by Butyrylcholine Esterase
}

\author{
Karel Komers ${ }^{\mathrm{a} *}$, Alexandr Čegan ${ }^{\mathrm{b}}$ and Marek Link ${ }^{\mathrm{a}}$
}

a Faculty of Chemical Technology, University of Pardubice, Department of Physical Chemistry, nám. Čs. legií 565, 53210 Pardubice, Czech Republic. Fax: (0042040) 6037068. E-mail: karel.komers @upce.cz

b Department of Biological and Biochemical Science

* Author for correspondence and reprint request

Z. Naturforsch. 57c, 1072-1077 (2002); received May 24/July 19, 2002

Acetylthiocholine, Butyrylcholine Esterase, Kinetics

Kinetics and mechanism of hydrolysis of acetylthiocholine by the enzyme butyrylcholine esterase was studied. The spectrophotometric Ellman's method and potentiometric pH-stat method were used for continuous determination of the actual concentration of the products thiocholine and acetic acid in the reaction mixture. The validity of the Michaelis-Menten (Briggs-Haldane) equation in the whole course of the reaction under used conditions was proved. The corresponding kinetics parameters $\left(V_{\mathrm{m}}\right.$ and $\left.K_{\mathrm{M}}\right)$ were calculated from the obtained dependences of concentration of thiocholine or acetic acid vs. time and compared. From this comparison the deciding kinetic role of the step producing thiocholine was derived. The values of initial molar concentration of the enzyme and of the rate constants of the kinetic model were estimated.

\section{Introduction}

This work creates a part of the research of new suitable inhibitors of cholinesterases as potential drugs against the Alzheimer demence. The inhibition effect of every new drug has to be compared with the uninhibited reaction of the same type. This paper deals with the kinetics and mechanism of uninhibited enzymatic decomposition of acetylthiocholine $(\mathrm{ATCH})$ by butyrylcholine esterase (BCHE) to thiocholine (TCH) and acetic acid (HA). The reaction course was measured in the initial stage and up to high conversion by two independent methods, i.e. by continuous measurement of the dependence of either concentration of thiocholine $[\mathrm{TCH}]$ vs. time $(t)$ using the Ellman's method (Ellman, 1961) or [HA] vs. $t$ by the potentiometric $\mathrm{pH}$-stat method (Giacobini, 2000).

\section{Materials and Methods}

\section{Theory}

The formal reaction scheme of enzymatic hydrolysis of the substrate S (i.e. ATCH) by the enzyme E (i.e. BCHE) to product $\mathrm{P}$ (i.e. $\mathrm{TCH}$ ) and HA can be expressed by the steps

$$
\begin{aligned}
& \mathrm{E}+\mathrm{S}=\mathrm{ES}(1), \quad \mathrm{ES} \rightarrow \mathrm{EA}+\mathrm{P}(2), \\
& \mathrm{EA}+\mathrm{H}_{2} \mathrm{O} \rightarrow \mathrm{E}+\mathrm{HA}(3)
\end{aligned}
$$

The symbols $=$ and $\rightarrow$ declare the reversible (equilibrium) and irreversible (one way) reaction steps with the rate constants $k_{1}, k_{1 \mathrm{r}}(r$ denotes the reverse step), $k_{2}, k_{3}$ and equilibrium constant $K_{1}=$ $k_{1 \mathrm{r}} / k_{1}$. A steady state for all reaction components including $\mathrm{E}$ (i.e. E and ES) exists during the whole reaction course on conditions that the initial concentration $[\mathrm{S}]_{\mathrm{o}} \gg[\mathrm{E}]_{\mathrm{o}}$ and the initial concentrations of all other componens are zero.

\section{Experimental}

Chemicals

Butyrylcholinesterase (BCHE): hydrolysate from the horse plasma, pressed in pellets ca. $6 \mathrm{~g}$, kept in refrigerator at $5^{\circ} \mathrm{C}$. Two pellets were solved in $200 \mathrm{ml}$ of demineralized water. This enzyme preparation was divided into the $10 \mathrm{ml}$ portions which were kept frozen at ca. $-6{ }^{\circ} \mathrm{C}$. For the daily experiments a portion was melted, kept at $5^{\circ} \mathrm{C}$ and used only that day.

Acetylthiocholine (ATCH) iodide: substrate from firm Sigma-Aldrich, Prague, CZ, kept at $5{ }^{\circ} \mathrm{C}$. From this substrate a fresh water solution of 
chosen volume and concentration was prepared for daily experiments.

5,5'-dithio-bis(2-nitrobenzoic acid) (DTNB, Ellman's reagent): Sigma-Aldrich, Prague, CZ, kept at laboratory temperature. From this substance the analytical aequous solution $2 \times 10^{-3} \mathrm{M}$ was prepared and kept at ca $5^{\circ} \mathrm{C}$.

Buffer: Sörensen's phosphate buffer $\mathrm{pH}$ 8.0, concentration $0.07 \mathrm{M}$, ionic strength $I=0.186 \mathrm{M}$ (defined by $\mathrm{NaCl} 0.1 \mathrm{M}$ ) was used. The buffer was prepared from $\mathrm{Na}_{2} \mathrm{HPO}_{4} .12 \mathrm{H}_{2} \mathrm{O}$ and $\mathrm{KH}_{2} \mathrm{PO}_{4}$ (both p.a. quality, Lachema Brno, CZ). The reserve solution was kept in darkness at laboratory temperature.

\section{Methods and apparatus}

Ellman's method (Ellman, 1961) was realized by means of a diode-array spectrograph HP 8452A, Hewlett-Packard, USA. This method is based on the spectrophotometric determination of the yellow anion Y, produced by the reaction of thiocholine $\mathrm{P}$ from the reaction (2) with DTNB in the reaction mixture. $\mathrm{Y}$ has the maximum absorbance at $412 \mathrm{~nm}$ (A). The value of $\mathrm{A}$ is taken as proportional to the actual concentration of $\mathrm{P}$, thus $[\mathrm{P}]=$ A / $(\varepsilon \cdot d)$, where $\varepsilon$ is the absorption coefficient of $\mathrm{Y}$ at $412 \mathrm{~nm}$ and $d$ is the thickness of the cuvette. The value of $\varepsilon=14150 \mathrm{M}^{-1} \cdot \mathrm{cm}^{-1}$ was used (Dodds and Rivory, 1999). A glass cuvette with the total volume $30 \mathrm{ml}$ and optical path $2 \mathrm{~cm}$ provided with a glass propeller was used as the reactor. The cuvette was filled with chosen volumes of buffer pH $8(I=0.14)$, DTNB solution and enzyme preparation. This mixture was thermostated at $25^{\circ} \mathrm{C}$. The reaction was started by fast $(<1 \mathrm{~s})$ homogenisation of the chosen volume of ATCH solution in the vigorously mixed reaction mixture. The initial concentrations of reactants are given in the description of single experiments in the chapter Results.

pH-stat method (Giacobini, 2000)

The $\mathrm{pH}$-stat was constructed by the combination of the potentiostat Automatic Titrimeter OP-506, Automatic Burette OP-930 (both Radelkis, Budapest, Hungary) and usual PC. The method is based on the determination of the actual concentration of the acetic acid [HA] produced in the step (3). This is realized by the continuous titration of HA with the analytical solution of $\mathrm{NaOH}$ keeping the $\mathrm{pH}$ of the reaction mixture at chosen constant (here $\mathrm{pH}$ 8.0) value, checked by the couple glass electrode - saturated $\mathrm{AgCl}$ electrode. From this measurement the dependence volume of analytical solution of $\mathrm{NaOH}(V)$ vs. $t$ is obtained. The $V$ value can be simply transformed to [HA] in the reaction mixture

$$
[\mathrm{HA}]=V \cdot[\mathrm{NaOH}] /\left[(1+1.67) \cdot V_{\mathrm{t}}\right]
$$

where the number 1.67 respects the amount of $\mathrm{NaOH}$ spent for neutralisation of the dissociated part of the acid thiocholine (Brestkin et al., 1974) and $V_{\mathrm{t}}$ is the total volume of the reaction mixture. In this method any buffer must not be principially used. Further, the reaction mixture must not be in the contact with the air because of present $\mathrm{CO}_{2}$ which reacts at $\mathrm{pH} 8$ immediately with the reaction mixture and decreases continuously its $\mathrm{pH}$ value. This complication was eliminated using the mixture of nitrogen and helium above the reaction mixture. The ionic strength was kept at the same value as in Ellman's method $(I=0.14 \mathrm{~m})$ by means of water solution of $1 \mathrm{~m} \mathrm{NaCl}$.

The reaction was carried out in a glass closed vessel $100 \mathrm{ml}$ thermostated at $25^{\circ} \mathrm{C}$ with an electromagnetic stirrer. The vessel was filled at first with the chosen amounts of BCHE preparation, water and $\mathrm{NaCl}$ solution. This mixture was kept under inert atmosphere and its $\mathrm{pH}$ value was adjusted to 8.0 by means of the aequous solution of $\mathrm{NaOH}$ under continuous control by galvanic couple mentioned above. The reaction was started by fast addition of the chosen volume of ATCH solution into the vigorously mixed reaction mixture. At the same time the automatic continuous addition of chosen analytical solution of $\mathrm{NaOH}$ and the on-line PC registration of its added volume $V$ vs. $t$ were started. The total initial volume of the reaction mixture was $36 \mathrm{ml}$, its increase during the addition of $\mathrm{NaOH}$ solution was ca $10 \%$ and was respected in the calculation of [HA] actual concentrations. The initial concentrations of reactants are given in the description of single experiments in the chapter Results.

The kinetics of hydrolysis of ATCH was studied by means of dependences $\mathrm{A} \approx[\mathrm{P}] \equiv[\mathrm{TCH}]$ vs. $t$ (Ellman's method) and $V \approx$ [HA] vs. $t$ (pH-stat method) 1) without $\mathrm{BCHE}, 2$ ) with $\mathrm{BCHE}$ at the a) start, b) whole course of the reaction at constant 
$[\mathrm{BCHE}]_{\mathrm{o}}, \mathrm{pH} 8$, ionic strength $0.14 \mathrm{M}(\mathrm{NaCl})$ and temperature $25^{\circ} \mathrm{C}$.

\section{Results}

Hydrolysis of ATCH by BCHE at start of the reaction

The nonenzymatic ATCH decrease $(0.11 \%$ w/w after 16 min of the reaction) can be fully neglected in the case of its parallel much faster enzymatic hydrolysis by BCHE.

\section{Ellman's method}

The mixture of phosphate buffer $0.05 \mathrm{M}$ and DTNB $2 \times 10^{-4} \mathrm{M}$ was used as the comparing standard solution. The initial reaction mixture consisted of the phosphate buffer $0.05 \mathrm{M}$, [DTNB $]_{\mathrm{o}}=$ $2 \times 10^{-4} \mathrm{M}$ and $[\mathrm{BCHE}]_{\mathrm{o}}=0.1 \mathrm{ml}$ of the enzyme preparation. The total volume of the reaction mixture was $12 \mathrm{ml}$. The series of dependences $A$ vs. $t$ was measured with various $[\mathrm{ATCH}]_{\mathrm{o}}$. From the linear initial parts of these dependences the saturation curve $v_{\mathrm{o}}{ }^{\prime}=d A / d t$ vs. $[\mathrm{ATCH}]_{\mathrm{o}}$ was calculated - see Fig. 1, curve a. The monotoneous form of the curve without decrease of $v_{\mathrm{o}}{ }^{\prime}$ at high $[\mathrm{ATCH}]_{\mathrm{o}}$ values indicates no inhibition of the reaction by the substrate ATCH. Comparison of the experimental data with the Michaelis-Menten equation

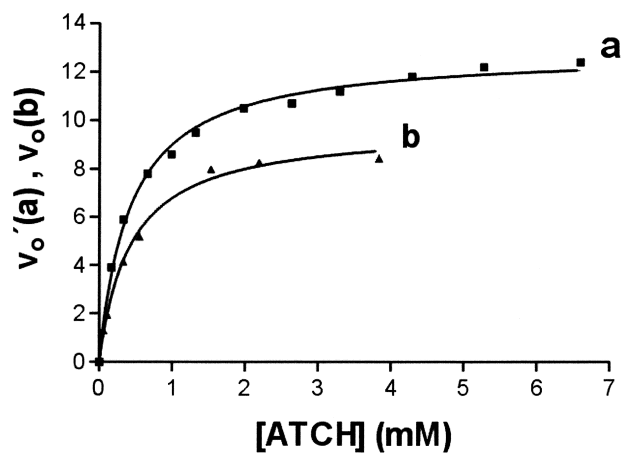

Fig. 1. Enzymatic hydrolysis of ATCH by BCHE measured at the start of the reaction by Ellman's method (dependence a: $v_{\mathrm{o}}{ }^{\prime}(\mathrm{a}) \equiv \mathrm{d} A / \mathrm{d} t \quad\left[\mathrm{mAU} \cdot \mathrm{s}^{-1}\right] \equiv$ $\varepsilon \cdot \mathrm{d} \cdot \mathrm{d}[\mathrm{TCH}] / \mathrm{d} t$ vs. $t$ ), pH-stat method (dependence b: $v_{\mathrm{o}}(\mathrm{b}) \equiv \mathrm{d}[\mathrm{HA}] / \mathrm{d} t\left[\mathrm{~mm} \cdot \mathrm{s}^{-1}\right]$ vs. $\left.\mathrm{d} t\right)$. The points represent experimental data The curves were obtained by comparison of these data with Equ. (5) by nonlinear regression with optimal parameters a) $K_{\mathrm{M}}=4.3 \times 10^{-4} \mathrm{M}$ and $V_{\mathrm{m}}=$ $4.2 \times 10^{-7} \mathrm{M} \cdot \mathrm{s}^{-1}$, b) $K_{\mathrm{M}}=4.3 \times 10^{-4} \mathrm{M}, V_{\mathrm{m}}=9.7 \times$ $10^{-7} \mathrm{M} \cdot \mathrm{s}^{-1}$.
$v=-\mathrm{d}[\mathrm{S}] / \mathrm{d} t=\mathrm{d}[\mathrm{P}] / \mathrm{d} t=\mathrm{d}[\mathrm{HA}] / \mathrm{d} t=$

$v^{\prime} /(\varepsilon \cdot \mathrm{d})=V_{\mathrm{m}} \cdot[\mathrm{S}] /\left(K_{\mathrm{M}}+[\mathrm{S}]\right)$

with respect to the value of $\varepsilon=14150 \mathrm{M}^{-1} \cdot \mathrm{cm}^{-1}$ and thickness of the cuvette $d=2 \mathrm{~cm}$, gave the values $K_{\mathrm{M}}=4.3 \times 10^{-4} \mathrm{M}$ and $V_{\mathrm{m}}=4.2 \times 10^{-7} \mathrm{M}$ $\mathrm{s}^{-1}$ (see Table II).

\section{pH-stat method}

was executed at the same temperature, $\mathrm{pH}, I$ and $[\mathrm{BCHE}]_{\mathrm{o}}\left(0.3 \mathrm{~cm}^{3}\right.$ of the enzyme preparation in $36 \mathrm{~cm}^{3}$ of the total volume of the initial reaction mixture). The analytical solutions of $\mathrm{NaOH} 3.6$ and $5.2 \mathrm{~mm}$ were used for the continuous titration of the arising HA. From the linear initial parts of the dependences $V$ vs. $t$ for various $[\mathrm{ATCH}]_{\mathrm{o}}$ the saturation curve $v_{\mathrm{o}}=\mathrm{d}[\mathrm{HA}] / \mathrm{d} t=-\mathrm{d}[\mathrm{ATCH}] / \mathrm{d} t$ vs. $[\mathrm{ATCH}]_{\mathrm{o}}$ was calculated (see Fig. 1, curve b). Comparison of the experimental data with (5) by nonlinear regression gave the values $K_{\mathrm{M}}=4.3 \times$ $10^{-4} \mathrm{M}$ and $V_{\mathrm{m}}=9.7 \times 10^{-7} \mathrm{M}^{\mathrm{s}-1}$ (see Table II).

\section{Hydrolysis of ATCH by BCHE up to high conversion}

The dependences $[\mathrm{P}] \equiv[\mathrm{TCH}]$ vs. $t$ (Ellman's method) or [HA] vs. $t$ (pH-stat method) were measured up to long reaction times. The results were compared with the integrated form of the equation (5).

\section{Ellman's method}

Three experiments $(1,2,3)$ were realized with $[\mathrm{ATCH}]_{\mathrm{o}}=2.63,3.95$ and $1.32 \times 10^{-5} \mathrm{M}$. The equation (5) can be after interation transformed by means of $A$ to the form

$t=K_{\mathrm{m}} \cdot \ln \left[A_{\infty} /\left(A_{\infty}-A\right)\right]+k \cdot A / V_{\mathrm{m}}$

which can be further retransformed to

$\left.(1 / A) \cdot \ln \left[A_{\infty}-A\right)\right]=\left(V_{\mathrm{m}} / K_{\mathrm{M}}\right) \cdot \mathrm{t} / A-k / K_{\mathrm{M}}$

where $A_{\infty}$ is the absorbance of the final reaction mixture $\left(t \rightarrow \infty\right.$, equilibrium) and $k=(\varepsilon \cdot d)^{-1}$. The dependence of the left side of (7) vs. $t / A$ gives a straight line. The values of $K_{\mathrm{M}}$ and $V_{\mathrm{m}}$ obtained from this linear regression (see Table Ia) were used as first estimates of the nonlinear regression of the 


\begin{tabular}{lcccccc}
\hline $\begin{array}{l}\text { Exper. } \\
\text { no. }\end{array}$ & \multicolumn{3}{c}{$\begin{array}{c}\text { Linear regression } \\
\text { according to a) (7) or b) }\end{array}$} & \multicolumn{3}{c}{$\begin{array}{c}\text { Nonlinear regression } \\
\text { according to a) (6) or b) (8) }\end{array}$} \\
\hline & $K_{\mathrm{M}} \times 10^{4} \mathrm{M}$ & $V_{\mathrm{m}} \times 10^{7} \mathrm{M} / \mathrm{s}$ & $R^{2}$ & $K_{\mathrm{M}} \times 10^{4} \mathrm{M}$ & $V_{\mathrm{m}} \times 10^{7} \mathrm{M} / \mathrm{s}$ & $R^{2}$ \\
\hline a) & 0.75 & 2.3 & 0.9946 & 0.39 & 1.3 & 0.9967 \\
2 & 2.2 & 6.2 & 0.9993 & 1.8 & 5.3 & 0.9999 \\
3 & 0.84 & 2.6 & 0.9921 & 1.9 & 3.1 & 0.9896 \\
\hline $\mathrm{b})$ & \multicolumn{7}{c}{} & & & & & \\
4 & 1.6 & 6.4 & 0.9917 & 1.5 & 6.0 & 0.9983 \\
5 & 1.9 & 6.2 & 0.9671 & 1.5 & 5.2 & 0.9910 \\
6 & 2.9 & 9.4 & 0.9586 & 1.4 & 5.1 & 0.9925 \\
\hline
\end{tabular}

Table I: Values of $K_{\mathrm{M}}, V_{\mathrm{m}}$ and $R^{2}$ calculated from the experimental data a) obtained by Ellman's method (experiments 1,2,3) and b) obtained by pH-stat method (experiments 4,5 , 6). $R$ is the correlation coefficient. experimental dependence $A$ vs. $t$ according to (6). An example of the results for the experiment 2 see in the Fig. 2a. The values of $K_{\mathrm{M}}, V_{\mathrm{m}}$ and the corresponding correlation coefficients $R$ calculated by the described linear and nonlinear regression for all three experiments 1, 2, 3 are also given in the Table Ia.

\section{a)}

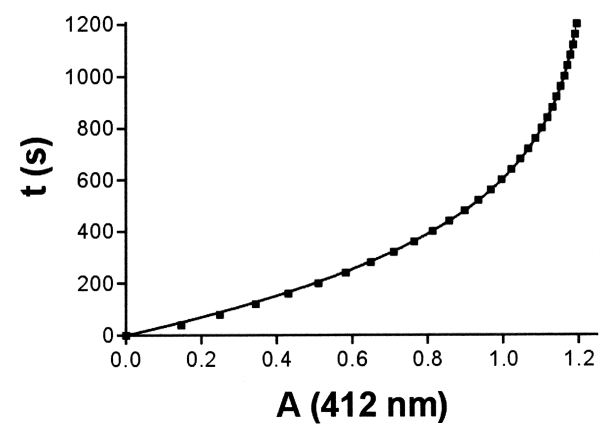

b)

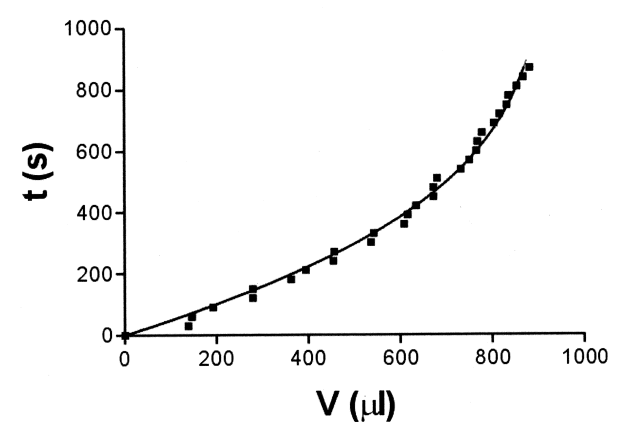

Fig. 2 a,b. Hydrolysis of ATCH by BCHE up to high conversion of ATCH. a) Ellman's method: Graphical comparison of the data from the experiment 2 with relation (6), $R^{2}=0.9999$. b) $\mathrm{pH}$-stat method: Graphical comparison of the data from the experiment 6 with relation (8), $R^{2}=0.9925$.

\section{pH-stat method}

The same initial conditions and concentrations were used as described in previous chapter " $\mathrm{pH}$ stat method" with exception of the value of $[\mathrm{ATCH}]_{\mathrm{o}}$. Three experiments $(4,5,6)$ were realized with $[\mathrm{ATCH}]_{\mathrm{o}}=1.24,1.10$ and $0.549 \times$ $10^{-4} \mathrm{M}$.

The Equ. (5) can be in this case transformed to the form

$t=K_{\mathrm{M}} \cdot \ln \left[V_{\infty} /\left(V_{\infty}-V\right)\right]+k^{\prime} \cdot V / V_{\mathrm{m}}$

and after linearization

$(1 / V) \cdot \ln \left[V_{\infty} /\left(V_{\infty}-V\right)\right]=$

$\left(V_{\mathrm{m}} / K_{\mathrm{M}}\right) \cdot t / V-k \cdot K_{\mathrm{M}}$

where $V_{\infty}$ is the volume of the used analytical solution of $\mathrm{NaOH}$ in equilibrium. The constant $k^{\prime}$ has, after introducing the used analytical concentration $[\mathrm{NaOH}]$, the total volume of the reaction mixture and the correction factor 0.67 (see equation (4)), the definition $k=1.6633 \times 10^{-5} \cdot[\mathrm{NaOH}]$. The dependence of the left side of (9) vs. $t / V$ is linear for all three experiments 4,5 and 6 . The values of $K_{\mathrm{M}}$ and $V_{\mathrm{m}}$ obtained from this linear regression (see Table Ib) were used as first estimates of the nonlinear regression of the experimental dependences $V$ vs. $t$ according to (8). An example for the experiment 6 is given in the Fig. 2b. The values of $K_{\mathrm{M}}, V_{\mathrm{m}}$ and $R$ calculated from this comparison are also given in the Table Ib.

We take the results from nonlinear regression as more exact than from linear regression in both types of experiments. 
Table II: Average values of $V_{\mathrm{m}}$ and $K_{\mathrm{M}}$ determined by Ellman's and $\mathrm{pH}$-stat method from the initial stage Equ. (5) and from the whole course - Equ. (6) or (8) of the enzymatic hydrolysis of ATCH by $\mathrm{BCHE}$ at $25^{\circ} \mathrm{C}$, pH 8.0, ionic strength $0.14 \mathrm{~m}$ and constant $[\mathrm{BCHE}]_{\mathrm{o}}$. Results correspond to data from (Breskin, 1974) measured at similar conditions: $V_{\mathrm{m}}=3.08 \times$ $10^{-7} \mathrm{M} \cdot \mathrm{s}^{-1}$ and $K_{\mathrm{M}}=5.4 \times 10^{-4} \mathrm{M}$.

\begin{tabular}{llcc}
\hline Dependence & Method & $V_{\mathrm{m}} \times 10^{7} \mathrm{M} \cdot \mathrm{s}^{-1}$ & $K_{\mathrm{M}} \times 10^{4} \mathrm{M}$ \\
\hline$v_{\mathrm{o}}$ vs. [ATCH] & Ellman's & 4.25 & 4.26 \\
Equ. (5) & pH-stat & 9.73 & 4.35 \\
\hline [ATCH] vs. $t$ & Ellman's & 3.27 & 1.37 \\
Equ. (6) or (8) & pH-stat & 5.43 & 1.45 \\
\hline
\end{tabular}

\section{Discussion}

Following conclusions can be made from the results given above:

1) The saturation curves measured by Ellman's and $\mathrm{pH}$-stat methods are without any extreme, i.e. no inhibition by substrate exists in the enzymatic hydrolysis of ATCH by BCHE at $\mathrm{pH} \mathrm{8.0,} \mathrm{ionic}$ strength $0.14 \mathrm{M}$ and $25^{\circ} \mathrm{C}$.

2) The validity of the Michaelis-Menten (or Briggs-Haldane) reaction mechanism represented by the equation (5) is fulfilled for this reaction at given conditions not only at its initial stage but also in the whole extent of the reaction times.

3 ) The values of the average kinetic parameters $V_{\mathrm{m}}$ and $K_{\mathrm{M}}$ in (5), determined both for the initial stage of the reaction and for high conversions of ATCH concentration by Ellman's spectral or $\mathrm{pH}$ stat potentiometric method, are practically identical, see Table II. They correspond also with the data from [Brestkin et al., 1974] measured at similar conditions: $V_{\mathrm{m}}=3.08 \times 10^{-7} \mathrm{M} \mathrm{s}^{-1}, K_{\mathrm{M}}=5.4 \times$ $10^{-4} \mathrm{M}$.

4) The step (2) with rate constant $k_{2}$ is rate determining in the reaction scheme described by the steps (1), (2) and (3). The Ellman's method determines namely the actual concentration of thiocholine $[\mathrm{P}]$, while the $\mathrm{pH}$-stat method measures the concentration of acetic acid [HA]. If the values of
$K_{\mathrm{M}}$ and $V_{\mathrm{m}}$ obtained by both methods are practically identical, then $k_{2}<<k_{3} \cdot\left[\mathrm{H}_{2} \mathrm{O}\right]$ and the faster step (3) does not make itself kinetically useful.

5) The values of single rate constants of the metioned reaction scheme and the unknown molar concentration of BCHE can be estimated from the received experimental data.

The estimate was realized by means of the computation program GEPASI (Mendes 1993, 1997; Mendes et al., 1998) allowing to solve the kinetics of the given reaction scheme numerically and to optimize the relevant kinetic constants with respect to the experimental dependences concentration vs. time of one or more reactants. The program requires in our case the stoichiometric equations of the scheme, initial composition of the reaction mixture, first estimation of the kinetic constants and the set (or sets) of experimental data. We used the reaction scheme represented by equations (1) and $\mathrm{ES} \rightarrow\left(\mathrm{H}_{2} \mathrm{O}, k_{2}\right) \rightarrow \mathrm{E}+\mathrm{P}+\mathrm{HA}$. The initial concentrations of the reactants were $\left.[\mathrm{S}]_{\mathrm{o}},[\mathrm{ES}]_{\mathrm{o}} \equiv[\mathrm{P}]_{\mathrm{o}} \equiv[\mathrm{HA}]_{\mathrm{o}}=0\right)$. The program allowed us to calculate not only the set of optimal kinetic constants $k_{1}, k_{1 \mathrm{r}}$ and $k_{2}$ but also to estimate the optimal value of the not known initial molar concentration of the used enzyme $[\mathrm{E}]_{\mathrm{o}}$.

The data from experiment 2 (Ellman's method) were used because of their best fitting to theoretical Equ. (7) - see $\mathrm{R}^{2}=0.9999$ in Table Ia. In this case $[\mathrm{S}]_{\mathrm{o}}=3.95 \times 10^{-5} \mathrm{M}$ and the calculated optimal estimations of the initial concentration of enzyme and of rate constants are: $[\mathrm{BCHE}]_{\mathrm{o}} \equiv[\mathrm{E}]_{\mathrm{o}}=$ $4.74 \times 10^{-8} \mathrm{M}, k_{1}=79266 \mathrm{M}^{-1} \cdot \mathrm{s}^{-1}, k_{1 \mathrm{r}}=7.436 \mathrm{~s}^{-1}$ and $k_{2}=24.34 \mathrm{~s}^{-1}$. The values of $K_{\mathrm{M}}=\left(k_{1 \mathrm{r}}+k_{2}\right) /$ $k_{1}=4.01 \times 10^{-5} \mathrm{M}$ and $V_{\mathrm{m}}=k_{2} \cdot[\mathrm{E}]_{\mathrm{o}}=1.15 \times$ $10^{-6} \mathrm{M} \mathrm{s}^{-1}$, calculated from these data, correspond well with the relevant values in the second line of Table Ia.

\section{Acknowledgement}

This work was financially supported by the grant of FRVŠ 1615-2001 and by Czech Ministerium of Education, Health and Sport, research project CZ 310008-2010-3340. 
Breskin A. P., Zukovskij J. G. and Sipenkova T. M. (1974), Hydrolysis of choline and thiocholine by cholinesterases (in Russian). Biochimia 39, 13-18.

Dodds H. M. and Rivory L. P. (1999), The mechanism of the inhibition of acetylcholinesterase by irinotecan (CPT-11). Mol. Pharmacol. 56, 1346-135.

Ellman G. L., Courtney K. D., Andres V. Jr. and Featherstone R. M. (1961), A new and rapid colorimetric determination of acetylcholinesterase activity. Biochem. Pharmacol. 7, 88-95.

Giacobini E. (editor) (2000), Cholinesterases and Cholinesterase Inhibitors. Martin Dunitz Ltd. London, pp. 139-144.
Laidler K. J. (1958), The Chemical Kinetics of Enzyme Action. Oxford Press, pp. 64-65.

Mendes P. (1993), GEPASI: a software package for modelling the dynamics, steady states and control of biochemical and othes systems. Comput. Appl. Biosci. 9, $563-571$.

Mendes P. (1997), Biochemistry by numbers: simulation of biochemical pathways with Gepasi 3. Trends Biochem. Sci. 22, 361-363.

Mendes P. and Kell D. B. (1998), Non-linear optimization of biochemical pathways: application to metabolic engineering and parameter estimation. Bioinformatics 14, 869-883. 